\section{Initial Experience of the Training Centre of Minimally Invasive Surgery at Ahli Arab Hospital in Gaza}

\author{
Skaik I H S,MD,MSc,CABS,FRCSEd, \\ Tawil S, MD,FRCSI, \\ Madhoun A,CABOG,CJBOG, \\ Naim F,MD, \\ Khaldi $Y, M D$, \\ Ayad M,MD, \\ Meinero $\mathrm{M}, \mathrm{MD}$
}

https://doi.org/10.33976/IUGNS.30.1/2022/3

\begin{abstract}
:
Background: Minimally Invasive Surgery (MIS) training outside operation room is still done by simulation in different training centers worldwide. Strong validity of such a training was evidenced using either the physical simulator (trainer box) or a biological model or a virtual reality (VR) or an animal model Currently MIS is rapidly spreading worldwide in different surgical centers depending on the fact that MIS training is an essential prerequisite for any surgeon even with a vast experience in open surgery. A well-structured proficiency-based curriculum is essential to provide training for individuals who need to acquire MIS skills.
\end{abstract}

Aim: To prove the efficiency and accuracy of training laparoscopic skills on combination of physical simulator as the dry module to be scored by a modified McGill Inanimate System for Training and Evaluation of Laparoscopic Skills (MISTELS) scoring system and on laparoscopic simulator as the wet module (Full Turkey model) using the Global Operative Assessment of Laparoscopic Surgery (GOALS) scoring items.

Methods: One hundred and thirty-nine surgeons of different surgical specialties, age and experience levels (during the period from July 2018 to July 2019) were subjected to this curriculum-based training. All trainees received the basic cognitive knowledge in groups of fifteen to eighteen. In the hands on training each group is divided into three subgroups to fit the available six fundamental laparoscopic surgery (FLS) training boxes. Trainees are monitored by at two mentored per trainer in the different FLS skills and tasks. A modified (MISTELS) was used to score the five Fundamental Laparoscopic Surgery (FLS) skills and tasks that are the standard of the Society of American Gastroenterology Endoscopic Surgery (SAGES). Modifications entail the scoring time to be in minutes rather than in seconds. Some extra-activities were added to the first three skills/tasks. A score sheet was designed for each task considering both the scoring time and penalties. In Wet lab, not only the five tasks were repeated but also a complementary skill such as Veress needle insertion, port insertion and camera manipulation together with dissection e.g. intracorporeally in cholecystectomy were provided through a full Turkey model on a laparoscopic simulator. Trainees' performance was measured with integration of cognitive knowledge post-testing, score in the modified MISTEL in dry lab and by the Global Operative Assessment of Laparoscopic Surgery (GOALS) scoring in wet laboratory. The mean of total score of the trainee before training was 35.28 while after training was 82.59 but Cronbach's Alpha value in the pre and post testing scored 0.778 and 0.799 respectively Results: Majority of trainees showed improvement in all measured domains in different stations. In cognitive knowledge the mean score difference between the pre and post testing was 50.1 and 72.14 respectively. This is statistically significant as shown in the student T-test value of 19.13. This indicates that the trainees are having some knowledge but definitely refined and improved on post testing.

In Dry Lab there is a dramatic improvement in the post testing compared to pretests where there was a clear statistical significance of a P value of 0.01 in all the five skills and tasks between the pre and post test of each. In wet Lab the Global Operative Assessment of Laparoscopic Surgery (GOALS) scoring system Which is used to assess skill of surgeons in clinical settings in OR is used to simulate clinical sessions on a Full Turkey Model on laparoscopic simulator set. GOALS scoring in Full Turkey model proves its feasibility and efficiency in most trainees where Mean score was 84.1, The Median 84.0, and the Std $=$

5.38. Construct validity of this triad methodology of cognitive knowledge, dry lab and wet lab of full Turkey model is evident among different trainees of different groups with no florid significance of different surgeons in relation scores achieved and age group proving validity of this type of training. There is no statistical differences between age group and the final score of overall training the mean average of the trainees ages less than 35 years old was $81.2 \%$ followed by the trainees above 45 years old $79.7 \%$ with very simple difference in mean with trainees aged between 35 years old to 45 years old $79.6 \%$.

Conclusion: MIS training integrating a triad of training modules of MIS cognitive knowledge, traditional physical box trainer and a biological wet lab on a full Turkey model is fairly feasible and effective in the acquisition of fundamental laparoscopicgskills and tasks. Global Operative Assessment of Laparoscopic Skills (GOALS) can be a valid tool to assess trainees outside operation room.

\section{Keywords:}

Minimally Invasive Surgery Training, FLS, Cognitive Knowledge, Dry Lab, Wet Lab, Full Turkey Model, GOALS, Construct Validity, Miller's Pyramid 


\section{Introduction:}

Currently minimally invasive surgery has become an integral part of operative management in virtually every field of surgery, including, general, gynecologic, urology, thoracic, arthroscopy and other visceral specialties. Technological advances in surgery ranging from laparoscopic instruments, to stapling devices, to endoscopic technology, brought new challenges for operating room (OR) nurses, surgical residents, and surgeons alike (1).

There is no doubt that Halstedian training model produced several leaders in the field of surgery but the curriculum-based training is inceasingly coming up since the twentieth century for surgical education reaching a certain proficiency level $(2,3)$

There are different training programs that are based mainly training by simulation. This simulation can be on one or on a combination of a physical training box or a virtual reality (VR) simulator or on an animal and ultimately in the operation room. However, the learning curve required to obtain laparoscopic expertise has been an issue in medical community. Laparoscopic surgery training laboratory was developed to overcome this barrier. Most available MIS training programs are curriculum based considering recommendations of international scientific societies such as SAGES in the states and European and Indians. This led to the development of skill laboratories that allowed surgeons to develop laparoscopic skills without putting patients at risk $(4,5,6,7,9,10,11)$.

Moreover, it has been proved that surgeons who are expert in open surgery they cannot do the same operation laparoscopically without gaining skills in MIS otherwise risk to patients is there! (12)

By simulation the trainee will not acquire only psychomotor skills but also the proper perception together with eye and hand coordination that has shown to decrease the learning curve in performing laparoscopic. Procedures. This is the minimum of objective assessment that should be performed before allowing residents to be active surgical team member in the operating room. This is reflected on decreasing the fundamental errors in the technique of laparoscopic cholecystectomy as proved by a broad of surgeons in the United States. ${ }^{(13)}$

The McGILL Inanimate System for Training and Evaluation of Laparoscopic Skills (MISTELS) ${ }^{(14)}$ which is a tool of five skills and tasks that are evaluated by a precise objective score system. It is used widely to assess MIS training process, and the metrics associated with MISTELS have been extensively evaluated and shown to be reliable and valid. The Society of American Gastrointestinal and Endoscopic Surgeons (SAGES) has incorporated MISTELS as the manual skills component of its Fundamentals of Laparoscopic Surgery program. Miller's pyramid ${ }^{(\mathbf{1 5})}$ which is used to assess the clinical proficiency level of the trainees can still be used in MIS training with modifications.

\section{Methodology and training tools:}

One hundred and thirty-nine surgeons of different professional levels were subjected to this training. An MIS training curriculum is developed. A well-equipped MIS training centre is established in Ahli Arab Hospital (AAH) with audio-visual, direct transmission from OR and an e-library. In this centre there are six FLS physical simulator training boxes for Dry and part of wet labs and a laparoscopic tower equipped with a medical monitor, light source and a camera processor to operate on a full chicken/Turkey model as the main wet lab. Herein the Full Turkey model was coined replacing the Full Chicken model tried before ${ }^{(\mathbf{1 5})}$. The main rational of training in these two modules is that the same skills/tasks done in dry lab are repeated in wet lab. This is in addition they are complementary to each other in terms of verses needle insertion, port insertion and camera manipulation and handling biological tissues in the turkey model. However, the selfconfidence of the trainee is being built although performing the different skills and tasks in both modules.

According to the curriculum they all trainees received the basic cognitive knowledge in groups each is made of a number of fifteen to eighteen trainee's subgroups where each subgroup is again divided into five or six trainees to fit the available six fundamental laparoscopic surgery (FLS) training boxes fulfilling the 
objective that each trainee is his/her own box and monitored by two mentors/instructors per trainer in the different FLS skills and tasks.

This study incorporates MISTEL tool into an improvised Miller's pyramid to assess the proficiency of the trainees by a net score of each trainee by summation of three scores in cognitive knowledge, dry lab and wet lab (full Turkey model). All activities done by each trainee is recorded and checked by the instructors in his/her log book.

According to the curriculum they all received the basic cognitive knowledge in groups each is made of a number of fifteen to eighteen trainees subgroups where each subgroup is again divided into five or six trainees to fit the available six fundamental laparoscopic surgery (FLS) training boxes fulfilling the objective that each trainee is his/her own box and monitored by at least two mentors/instructors per trainer in the different FLS skills and tasks.

Cognitive Knowledge is aimed to cover the main fundamental and clinical MIS issues that are addressing MIS equipment and instruments, energy Sources, perioperative patient Considerations, Anesthesia in MIS, ergonomics, Pneumoperitoneum, Abdominal Access and trocar placement, tissue handling and biopsy techniques, hemorrhage and Hemostasis control in laparoscopy, tissue Approximation, exiting the abdomen, postoperative Care and documentations in MIS $^{(\mathbf{1 6})}$.

Each of the presentations is enriched with an on line already related recoded video such as laparoscopic anatomy, ergonomic in the OR, laparoscopic equipment, entry access (direct trocar, entry palmer, open entry, veress needle, vision entry), arthroscopy videos, diagnostic laparoscopy, complications on laparoscope, ovarian cystectomy, bleeding in endoscopic surgery, missed loops, myomectomy, pelvic adhesion with adhesiolysis, cholecystectomy, appendectomy... etc.

Scoring for cognitive knowledge (out of 25): is the score gained by the post test multiple choice questions

\section{Dry Lab (physical simulator):}

In Dry lab the main five skills/tasks of FLS used in original MISTELS (McGill Inanimate System for Training and Evaluation of Laparoscopic Skills) tasks were modified from the original testing format to facilitate a simplified training format that is easier to score and amenable to real-time assessment for proficiency-based training with immediate feedback to the learner and easy to score by the instructor.

Modifications done include two entities. The first was in the scoring issue where the scoring time was measured in minutes rather than in seconds (Fig 1.a, Fig 1.b). A minimal target of one minute was unified in all tasks but the maximum is kept the same together with the upper limit of repetitions. The second modifications was in adding some other extra models to the first three tasks. (Fig 2.a, Fig 2.b)

In skill one we added different shapes and texture of objects in addition to pegs where this is achieved in a training time limit but the post test is to be done on the standard peg transfer triangles.

$\mathrm{n}$ Skill Two, we added different shapes to cut like triangle, oval and many other irregular shapes but still the post test is on the standard circle. In the third task we added a session of knotting and doing different types of knots eg Reoder's knot, sliding knot, reef knotting etc. but still the post test is done on the standard loop but to be created by the trainee him/herself.
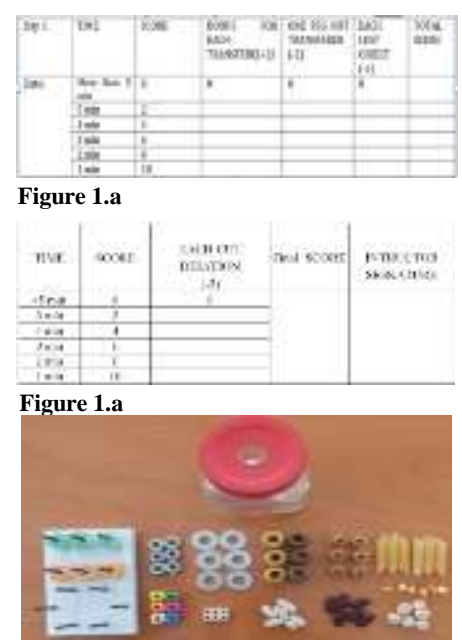

Figure 2.a

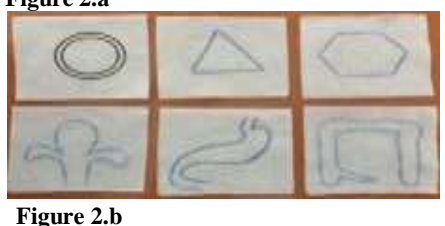




\section{Scoring in Dry Lab (out of 50):}

The original MISTELS tasks were modified from the original testing format to facilitate a simplified training format that is easier to score and amenable to real-time assessment for proficiency-based training with immediate feedback to the learner and easy to score by the instructor.

The basic FLS models are implemented with minor modifications. Modifications entailed both the skills/tasks (extra tasks but the originals are the standard and scoring is built on the standards) and the score sheets. However, the same FLS material in each skill/task was kept the same in the pre and post-testing.

\section{Wet Lab (Laparoscopic simulator on Full Turkey model):}

The wet Lab is complementary to the dry lab but on biological tissues in the full Turkey model (Fig 3.a, Fig 3.b, Fig3.c, Fig 3.d). This is in addition of doing the same five skills/tasks. This is fulfilled by incorporating some other fundamental MIS skills e.g. Veress needle insertion, port insertion, camera manipulation, and techniques of dissection. Training here is provided through a formal laparoscopic simulator that is composed basically of the standard OR laparoscopic trolley containing a medical monitor, light source, and a camera processor and all needed lap instruments.

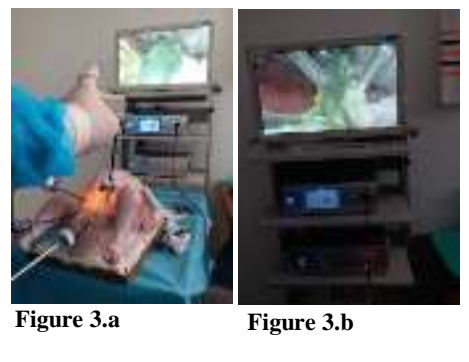

A full Turkey model was implanted where the turkey is prepared where the neck is taken to trainer box and the abdomen of the turkey is evacuated of bowel from the gastro-esophageal junction leaving the oesophagus down to the terminal intestine leaving about $5 \mathrm{~cm}$ as a tubular structure to practice on. The left lobe of the liver is excised leaving the right lobe with the gall bladder and the attached piece of bowel for dissection and cholecystectomy. Selected wide caliber loops if intestine are selected for manipulation in the trainer box for intubation by a piece of feeding tube and doing suturing and end to end anastomosis. Turkey's neck was

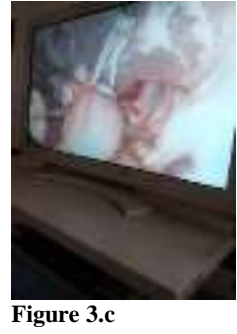

Figure 3.c

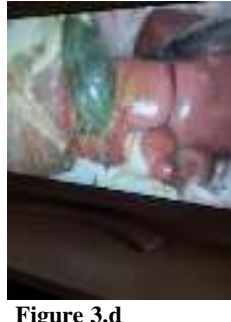

Figure 3.d

subjected to dissection, cutting and suturing on trachea and esophagus with intubations.

Scoring in Wet Lab (out of 25): Scoring in wet lab using the GOALS criteria that address five domains in namely Depth Perception, Bimanual dexterity, Efficiency, Tissue Handling and Autonomy. Highest score for each domain is 5.

Scoring is done by two instructors for each candidate based on the instructorobservation considering the Global Operative Assessment of Laparoscopic Skills (GOALS) items for evaluation ${ }^{(17,18)}$.

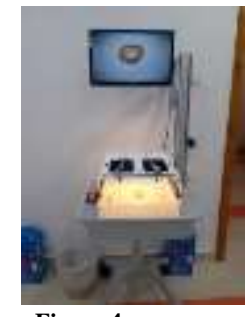

Figure 4.a

\section{Results and Discussion}

Two main domains are going to be discussed. The first is the socio-demographic data of the trainees and their satisfaction and the second is the results of in the three training modules; the cognitive knowledge, dry lab and wet lab. Descriptive statistics frequencies like mean, Median, Standard Deviation, and the Paired sample t-test to analyze both the Socio-demographic characteristics of the study population, and the results of training before and after for each trainee in each module. 


\section{I- Socio-demographic characteristics of the trainees and their Satisfactions:}

\section{I.1- Distribution of the study participants according to their Personal data}

Table (1) shows the distribution of participant's characteristics according to their personal data e.g. gender, age, place of work and specialty.

There are $58.3 \%$ of study participants are male while $41.7 \%$ female, regarding the age $38.8 \%$ were less than 30 years old , $30.9 \%$ were from 30 to 40 year old, $20.9 \%$ from 41 to 50 years old, while $9.4 \%$ above 50 years old. The mean age of participant 35.67 years old, almost $80.0 \%$ of the participant work in Governmental hospital, $18.0 \%$ work in NGO's hospital, only $2.2 \%$ in work in other places UNRWA and Private, regarding to specialty 57.6\% were Gynecology, 20.9\% General Surgery, 8.6\% General Doctor and $5.0 \%$ Pediatric Surgery, $74.8 \%$ were live in Gaza city, $10.1 \%$ in rafah, and $6.5 \%$ in Khanyounis.

\begin{tabular}{|l|c|c|}
\hline Items & Nu. & \% \\
\hline Gender & 81 & 58.3 \\
\hline Male & 58 & 41.7 \\
\hline Female & $\mathbf{1 3 9}$ & $\mathbf{1 0 0 . 0}$ \\
\hline Total &
\end{tabular}

\begin{tabular}{|c|c|c|}
\hline \multicolumn{3}{|l|}{ Age } \\
\hline Less than 30 Years old & 54 & 38.8 \\
\hline From 30 to 40 Years old & 43 & 30.9 \\
\hline From 41 to 50 Years old & 29 & 20.9 \\
\hline Above 50 Years old & 13 & 9.4 \\
\hline Total & 139 & 100.0 \\
\hline \multicolumn{3}{|c|}{ Mean 35.676, Median 32.00, Std, 9.705} \\
\hline \multicolumn{3}{|l|}{ Place of Work } \\
\hline Governmental Hospital & 111 & 79.9 \\
\hline NGO's Hospital & 25 & 18.0 \\
\hline Other (Private, UNRWA) & 3 & 2.2 \\
\hline Total & 139 & 100.0 \\
\hline \multicolumn{3}{|l|}{ Specialty } \\
\hline Gynecology & 80 & 57.6 \\
\hline General Surgery & 29 & 20.9 \\
\hline General Practitioner & 12 & 8.6 \\
\hline Pediatric Surgery & 7 & 5.0 \\
\hline Urology & 4 & 2.9 \\
\hline Other (Arthroscopy, Neurosurgery, Orthopedic) & 7 & 5.1 \\
\hline Total & 139 & 100.0 \\
\hline \multicolumn{3}{|l|}{ Living Address } \\
\hline North & 5 & 3.6 \\
\hline Gaza & 104 & 74.8 \\
\hline Midzone & 7 & 5.0 \\
\hline Khanyounis & 9 & 6.5 \\
\hline Rafah & 14 & 10.1 \\
\hline Total & 139 & 100.0 \\
\hline
\end{tabular}

Table (1) Distribution of the study participants according to their Personal data 


\section{2 Distribution of the study participants according to their experience on laparoscopy and open surgery}

Table (2) shows the distribution of participant's characteristics according to their experience on laparoscopy and open surgery. There were $20.6 \%$ of study participants had some experience on laparoscopy while there were $79.4 \%$ of participant not having any!

The result shows that $47.1 \%$ had experience in open surgery less than 5 years, $32.4 \%$ had experience from 11 to 20 years, while $11.8 \%$ had experience more than 20 years, only $4.4 \%$ participate previously on laparoscopy courses training. This indicates that the vast majority of surgeons (about 96,6\%) did not attend any laparoscopic training courses before and hence the significance of implementing of this training and similar MIS courses.

\begin{tabular}{|l|c|c|}
\hline \multicolumn{1}{|c|}{ experience on laparoscopy } & Nu. \\
\hline \multicolumn{1}{|c|}{} \\
\hline Yes & 14 & 20.6 \\
\hline No & 54 & 79.4 \\
\hline Total & $\mathbf{6 8}$ & $\mathbf{1 0 0 . 0}$ \\
\hline The experience as & 13 & 92.9 \\
\hline Second Assistance & 43 & 7.1 \\
\hline First Assistance & $\mathbf{1 4}$ & $\mathbf{1 0 0 . 0}$ \\
\hline Total & \multicolumn{2}{|c|}{} \\
\hline
\end{tabular}

\begin{tabular}{|l|c|c|}
\hline \multicolumn{3}{|c|}{ Experience Years in open surgery } \\
\hline Less than 5 Years & 32 & 47.1 \\
\hline From 5 to 10 Years & 6 & 8.8 \\
\hline From 11 to 20 Years & 22 & 32.4 \\
\hline Above 20 Years & 8 & 11.8 \\
\hline Total & $\mathbf{6 8}$ & $\mathbf{1 0 0 . 0}$ \\
\hline Mean 9.88, Median 5.50, Std 8.63 & \multicolumn{2}{|c|}{} \\
\hline \multicolumn{3}{|c|}{ Previous participation on laparoscopy courses training } \\
\hline Yes & 3 & 4.4 \\
\hline No & 65 & 95.6 \\
\hline Total & $\mathbf{1 3 9}$ & $\mathbf{1 0 0 . 0}$ \\
\hline
\end{tabular}

Table (2) Distribution of the study participants according to their experience on laparoscopy and open surgery

\subsection{Evaluation of the trainees compliance and Satisfaction of the training process (among the last 68 trainees of the study)}

As clear in table (3) there were $86.8 \%$ of study participants evaluate the teaching methods of training good and $13.2 \%$ said it's sufficient. About the useful of this session $88.2 \%$ said it's good, $10.3 \%$ said it's sufficient, while only $1.5 \%$ said it's poor, regards to testing laparoscopic skill $76.5 \%$ of the participant said the skill of laparoscopic testing much, $22.1 \%$ said little, regards to Improving laparoscopic skills $61.8 \%$ said much, and $35.3 \%$ said some, regards to Improving performance on the laparoscopic simulator (Wet lab) $76.5 \%$ said much, $22.1 \%$ said some and $1.5 \%$ said little, regards to Training on new laparoscopic procedures $77.9 \%$ said much, $16.2 \%$ said some, while $5.9 \%$ said little (table 9). Interesting enough all trainees appreciated the training process and were enthusiastic to convey massage to other colleagues. This indicates smooth well planned curriculum structure and process of training. 


\begin{tabular}{|c|c|c|}
\hline Items & Nu. & $\%$ \\
\hline \multicolumn{3}{|c|}{ Teaching methods } \\
\hline Sufficient & 9 & 13.2 \\
\hline Good & 59 & 86.8 \\
\hline Total & 68 & 100.0 \\
\hline \multicolumn{3}{|c|}{ The session useful } \\
\hline Poor & 1 & 1.5 \\
\hline Sufficient & 7 & 10.3 \\
\hline Good & 60 & 88.2 \\
\hline Total & 68 & 100.0 \\
\hline \multicolumn{3}{|c|}{ Testing laparoscopic Skill } \\
\hline Little & 1 & 1.5 \\
\hline Some & 15 & 22.1 \\
\hline Much & 52 & 76.5 \\
\hline Total & 68 & $\mathbf{1 0 0 . 0}$ \\
\hline \multicolumn{3}{|c|}{ Improving laparoscopic skills } \\
\hline Little & 1 & 1.5 \\
\hline Some & 15 & 22.1 \\
\hline Much & 52 & 76.5 \\
\hline Total & 68 & 100.0 \\
\hline \multicolumn{3}{|c|}{ Improving performance on the laparoscopic simulator (Wet lab) } \\
\hline Little & 2 & 2.9 \\
\hline Some & 24 & 35.3 \\
\hline Much & 42 & 61.8 \\
\hline Total & 68 & $\mathbf{1 0 0 . 0}$ \\
\hline \multicolumn{3}{|c|}{ Training on new laparoscopic procedures } \\
\hline Little & 4 & 5.9 \\
\hline Some & 11 & 16.2 \\
\hline Much & 53 & 77.9 \\
\hline Total & 68 & $\mathbf{1 0 0 . 0}$ \\
\hline
\end{tabular}

Table (3) Distribution of the study participants according to their Post-Training Evaluation by The Trainees 


\section{Scores in the Training Modules:}

\section{II.1 Cognitive Knowledge: Pre-test, Post-test and Change percentage among Trainees:}

Table 4 shows the distribution of participant's characteristics according to their Cognitive as follows

\section{Cognitive Knowledge: Pre- test scoring:}

There are $23.7 \%$ of study participants were had a very poor and poor Cognitive, $57.6 \%$ had moderate Cognitive, and $18.7 \%$ had good Cognitive, the mean average of Cognitive was $51.42 \%$.

\section{Distribution of Pre-test Cognitive Knowledge result among trainees}

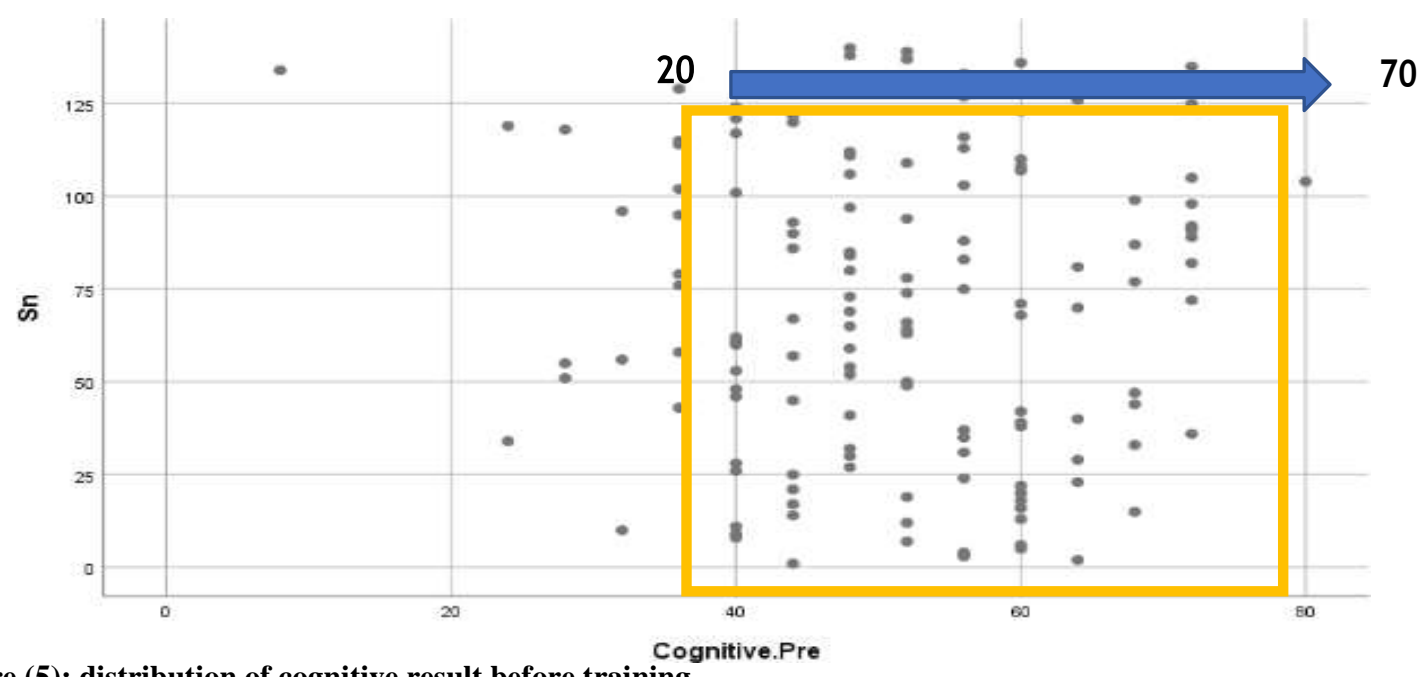

Figure (5): distribution of cognitive result before training

Fig (5) shows that the distribution of the cognitive score results before training is ranging between 30 to 70 for the trainees in pre-test, the most participant result were between 40 to 60 , and it's clear from the mean of distribution which51.42, equal in table (2) and the median was $52.0 \%$ and standard deviation was $12.46 \%$, This results shows that there were a difference between the trainees in cognition, This difference creates a great challenges for the trainers to work and deal with it through a flexible training program, to reach the level of convergence of awareness of all trainees.

\section{Cognitive Knowledge: Post-testing Scoring:}

There are $74.1 \%$ of study participants were had a good Cognitive, $13.7 \%$ had moderate Cognitive, and $12.2 \%$ had very good Cognitive, the mean average of Cognitive was $72.14 \%$. 


\section{Distribution of Cognitive result after training}

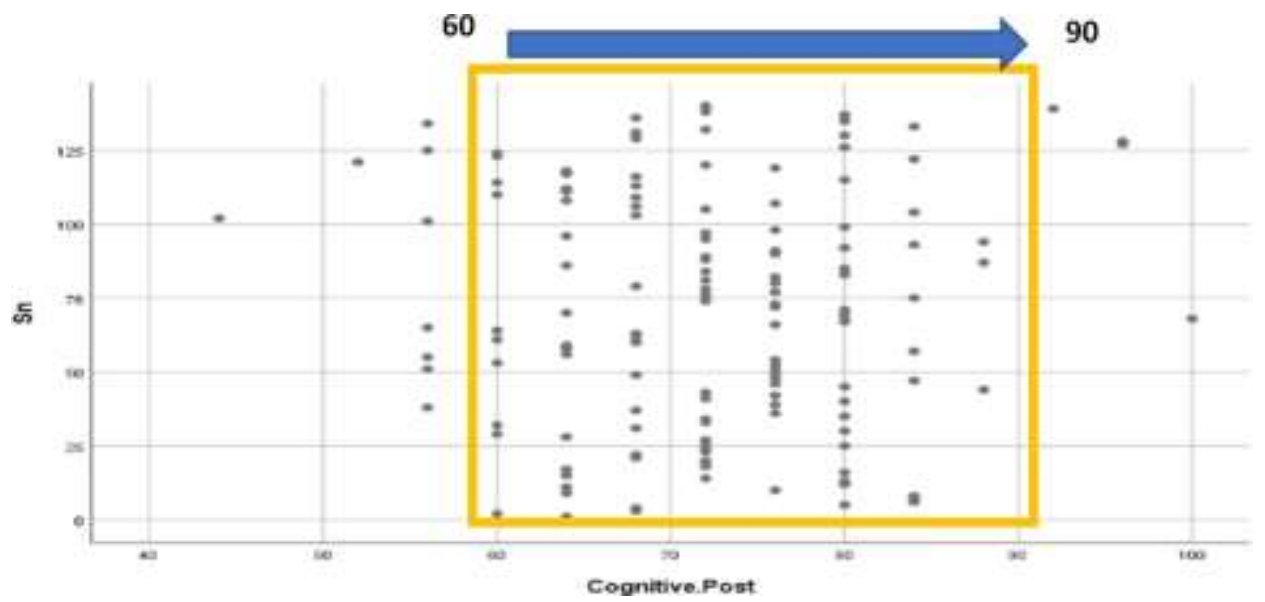

Figure (6): distribution of cognitive result after training

Fig (6) shows that the distribution of the cognitive score results after training is ranging between 60 to 90 for the trainees, the most participant result were between 70 to 80 , and few of them exceeded 80, it's clear from the mean of distribution in table above (1.2) which equal 72.14 , and the median was $72.0 \%$ and standard deviation was $9.33 \%$, This results shows that there were a positive difference between the trainees in cognition. These results confirm the ability of trainers to deal with previous differences in perception and training effectiveness.

\section{Change Percent of Cognitive before and after training}

There are $37.4 \%$ of study participants improve their Cognitive above than 50.0 percent, $24.4 \%$ improve their Cognitive from 31 to 50 percent, 20.9\%, improve their Cognitive less than $20 \%$ while $17.3 \%$ improve them cognitive from 21 to $30 \%$, the mean average of change percent was $50.69 \%$. Those figures indicate the importance of mastering MIS related knowledge before being involved in the hands-on sessions.

\begin{tabular}{|c|c|c|}
\hline Items & Nu. & $\%$ \\
\hline \multicolumn{3}{|l|}{ Cognitive before training } \\
\hline Very Poor $(0-20 \%)$ & 1 & 0.7 \\
\hline Poor (21 to $40 \%)$ & 32 & 23.0 \\
\hline Moderate (41 to $60 \%$ ) & 80 & 57.6 \\
\hline Good (61 to $80.0 \%)$ & 26 & 18.7 \\
\hline Very good (81 to $100 \%)$ & 0 & 0.0 \\
\hline Total & 139 & 100.0 \\
\hline \multicolumn{3}{|c|}{ Mean 51.42, Median 52.00, Std, 12.46} \\
\hline \multicolumn{3}{|l|}{ Cognitive after training } \\
\hline Very Poor $(0-20 \%)$ & 0 & 0.0 \\
\hline Poor $(21$ to $40 \%)$ & 0 & 0.0 \\
\hline Moderate (41 to $60 \%$ ) & 19 & 13.7 \\
\hline Good (61 to $80.0 \%)$ & 103 & 74.1 \\
\hline Very good (81 to $100 \%)$ & 17 & 12.2 \\
\hline Total & 139 & 100.0 \\
\hline \multicolumn{3}{|c|}{ Mean 72.14, Median 72.00, Std, 9.33} \\
\hline \multicolumn{3}{|c|}{ Change Percent of Cognitive before and after } \\
\hline 20 percent and Less & 29 & 20.9 \\
\hline From 21 to 30 Percent & 24 & 17.3 \\
\hline From 31 to 50 Percent & 34 & 24.4 \\
\hline Above 50 Percent & 52 & 37.4 \\
\hline Total & 139 & $\mathbf{1 0 0 . 0}$ \\
\hline \multicolumn{3}{|c|}{ Mean 50.69, Median 42.86, Std, 59.93} \\
\hline
\end{tabular}

Table (4) Distribution of the study participants according to their Cognitive Pre - post and change percentage 


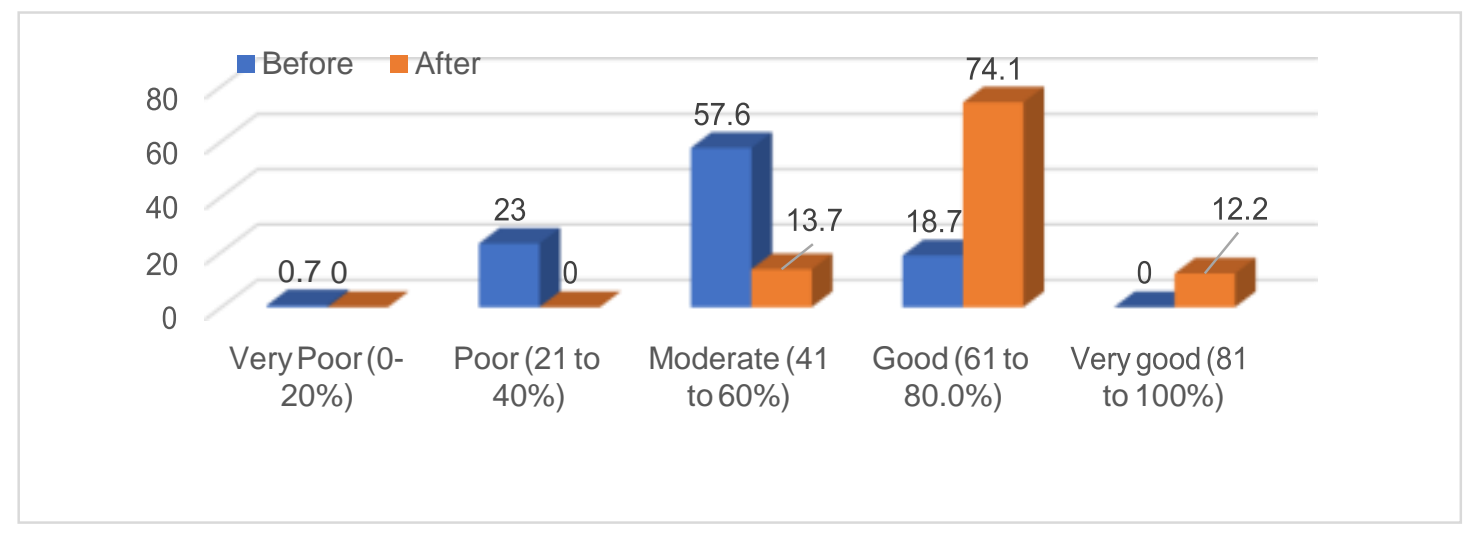

Figure (7): distribution of cognitive knowledge categories Pre and post training

According to the above figure the results shows that most of trainee had moderate cognitive knowledge may because of the information change between the doctors in their hospitals during practices while only $18.7 \%$ had a good cognitive knowledge, after training the variation of information between trainees the instructors was challenged to interactive presentation were considered for the all of levels to get up to same level.

\section{Inferential Statistics in Cognitive between Pre and Post-testing}

The combination of the pre-test results in the three activities of training is illustrated in figures 1,2 and 3 where there is clear improvement compared with the distribution of the score results of the post test. This improvement is statistically significant according to table 3 which mean there are statistical differences (sig. $\leq 0.05$ ). between cognitive pre and post-test, the mean of cognitive in pre-test training was $51.42 \%$ while post- training was $72.14 \%$.

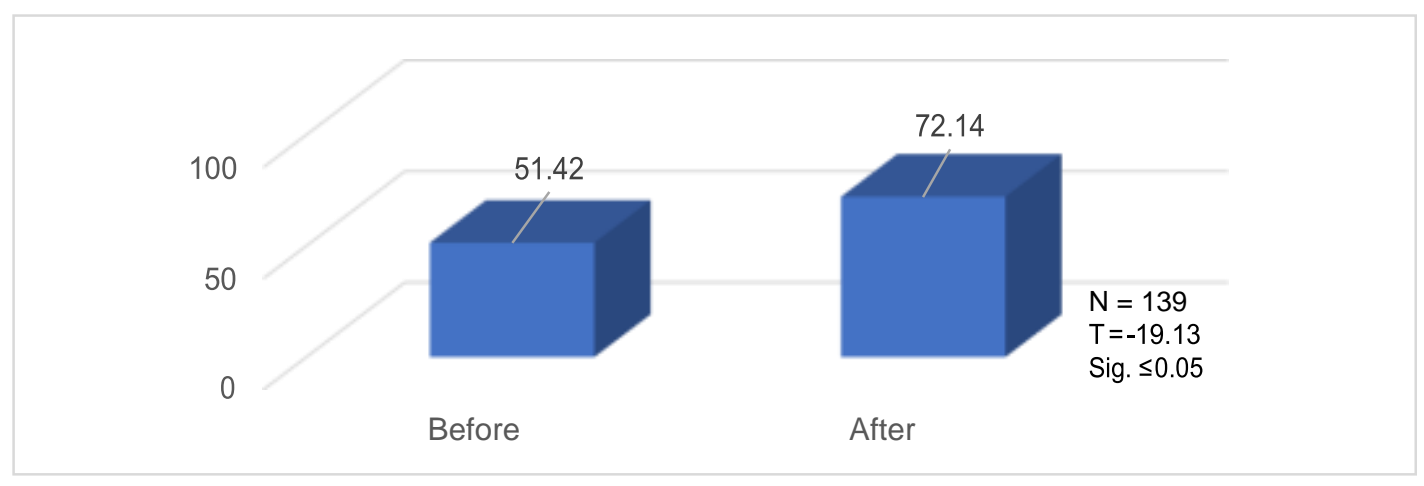

Figure (8): Distribution of mean score of cognitive before and after 
II.2 Dry Lab Skills and Tasks Scoring among Trainees:

II.2.1 Mean of total score of the trainees before and after training:

Table (5) shows that the mean of total score of the trainee before training was 35.28 while after training was 82.59,

\begin{tabular}{|c|c|c|c|c|c|c|c|}
\hline \multirow{2}{*}{ Skills/Tasks } & \multicolumn{2}{|c|}{ Before Training } & \multicolumn{2}{|c|}{ After Training } & \multirow{2}{*}{$\mathbf{T}$} & \multirow{2}{*}{ Sig. } & \multirow{2}{*}{ ICC* } \\
\hline & Mean & SD & Mean & SD & & & \\
\hline Peg transfer & 30.36 & 27.5 & 82.43 & 14.34 & 19.08 & 0.001 & 0.582 \\
\hline Precision Cutting & 32.90 & 26.64 & 75.98 & 14.81 & 17.02 & 0.001 & 0.439 \\
\hline Endo loop & 93.58 & 22.42 & 98.80 & 4.35 & 8.021 & 0.001 & 0.140 \\
\hline Extra Corporial & 24.48 & 26.34 & 76.99 & 16.34 & 22.07 & 0.001 & 0.512 \\
\hline Intra Corporial & 28.70 & 35.39 & 88.44 & 11.93 & 20.70 & 0.001 & 0.484 \\
\hline Total Score & 35.28 & 18.83 & 82.59 & 9.79 & 29.06 & 0.001 & \\
\hline Cronbach's Alpha & \multicolumn{2}{|c|}{0.779} & \multicolumn{2}{|c|}{0.799} & & & \\
\hline
\end{tabular}

Table (5) Distribution of the study participants according to their Skills and Tasks (Dry Lab)

- Interclass correlation coefficient

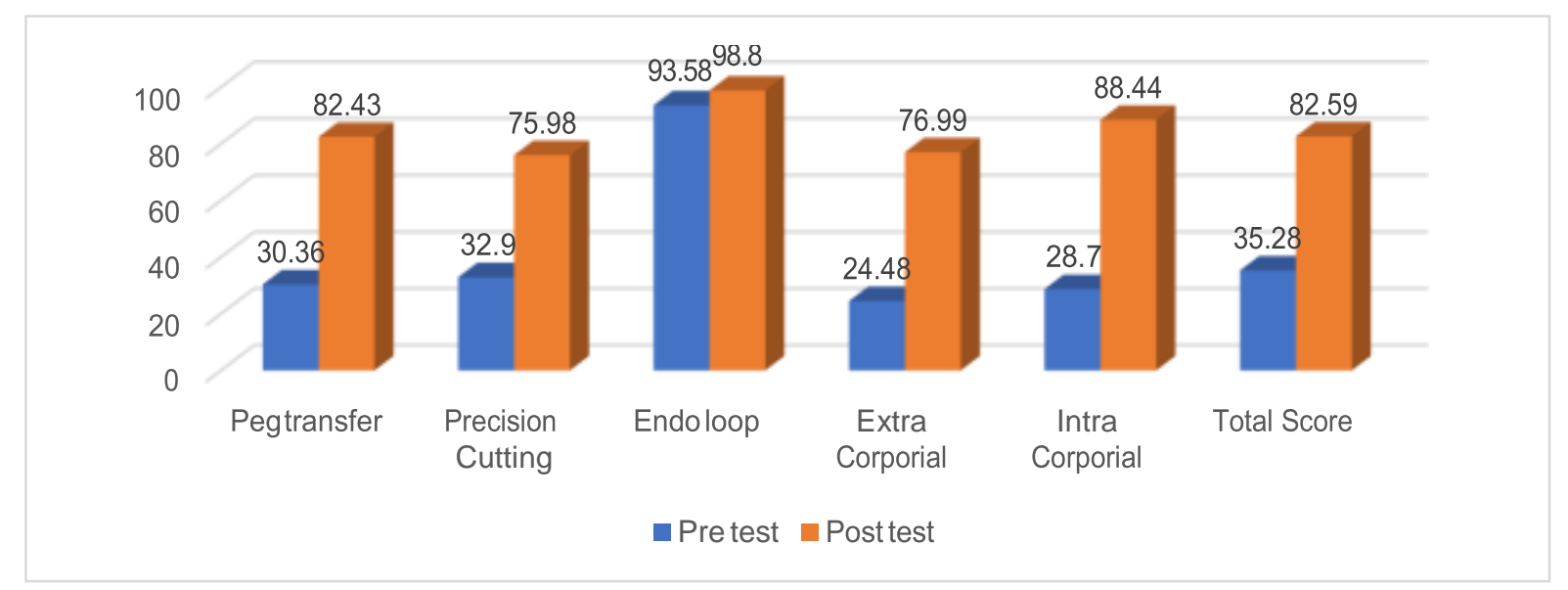

Figure (9): distribution of mean score of skills and tasks for Dry lab

\section{II.2.2 Distribution of the study participants according to their Skill Grades}

Table 6 shows the distribution of participant's characteristics according to their skill, all the participant had a transfer skill, $89.9 \%$ had a very good cutting skills while $10.1 \%$ had excellent in cutting skill, $89.2 \%$ had a very goof Endo Loop skill, and all the participant had a very good Extra and Intra corporeal Knot

\begin{tabular}{|c|c|c|c|c|c|c|}
\hline \multirow{2}{*}{ Items } & \multicolumn{2}{|c|}{ Good } & \multicolumn{2}{c|}{ Very Good } & \multicolumn{2}{c|}{ Total } \\
\cline { 2 - 7 } & Nu. & \% & Nu. & \% & Nu. & \% \\
\hline Transfer & 0 & 0.0 & 139 & 100.0 & 139 & 100.0 \\
\hline Cutting & 125 & 89.9 & 14 & 10.1 & 139 & 100.0 \\
\hline Ende loop & 124 & 89.2 & 15 & 10.8 & 139 & 100.0 \\
\hline Extra corporeal Knot & 139 & 100.0 & 0 & 0.0 & 139 & 100.0 \\
\hline Intra corporeal Knot & 139 & 100.0 & 0 & 0.0 & 139 & 100.0 \\
\hline
\end{tabular}

Table (6) Distribution of the study participants according to their Skill Grades 


\section{II.2.3 Dry Lab: Pre and Post-testing Percentage Trainees scoring:}

Table 7 shows the distribution of participant's characteristics according to their practices

\begin{tabular}{|c|c|c|}
\hline Items & No. & $\%$ \\
\hline \multicolumn{3}{|l|}{ Practices before training } \\
\hline Very Poor $(0-20 \%)$ & 41 & 29.5 \\
\hline Poor (21 to $40 \%)$ & 55 & 39.6 \\
\hline Moderate (41 to $60 \%$ ) & 31 & 22.3 \\
\hline Good (61 to $80.0 \%)$ & 12 & 8.6 \\
\hline Very good (81 to $100 \%)$ & 0 & 0.0 \\
\hline Total & 139 & 100.0 \\
\hline \multicolumn{3}{|c|}{ Mean 33.88, Median 32.00, Std, 17.82} \\
\hline \multicolumn{3}{|c|}{ Practices after training } \\
\hline Very Poor $(0-20 \%)$ & 1 & 0.7 \\
\hline Poor (21 to $40 \%)$ & 0 & 0.0 \\
\hline Moderate (41 to $60 \%)$ & 2 & 1.4 \\
\hline Good (61 to $80.0 \%)$ & 51 & 36.7 \\
\hline Very good (81 to $100 \%)$ & 85 & 61.2 \\
\hline Total & 139 & 100.0 \\
\hline \multicolumn{3}{|c|}{ Mean 82.32, Median 84.00, Std, 9.70 } \\
\hline \multicolumn{3}{|c|}{ Change Percent of practices before and after } \\
\hline Less than 100 percent & 46 & 33.1 \\
\hline From 101 to 200 Percent & 37 & 26.6 \\
\hline From 201 to 300 Percent & 22 & 15.8 \\
\hline Above 300 Percent & 34 & 24.5 \\
\hline Total & 139 & 100.0 \\
\hline
\end{tabular}

Table (7) Distribution of the study participants according to their Practices Pre - post and change percentage

This table (3) did show clearly how much is the improvement in perfoming the skills and tasks where trainees 85 of trainees scored very good but no one got any very good in the pretest. This must be a big impact of the training process 


\section{Pre-test scoring among the trainees in Dry Lab:}

There are $29.5 \%$ of study participants were had a very poor practice, $39.6 \%$ had poor practice, and $22.3 \%$ had moderate practices, while only $8.6 \%$ had a good practice, the mean average of practices was $33.88 \%$

\section{Pre-test Scoring among trainees in Dry Lab:}

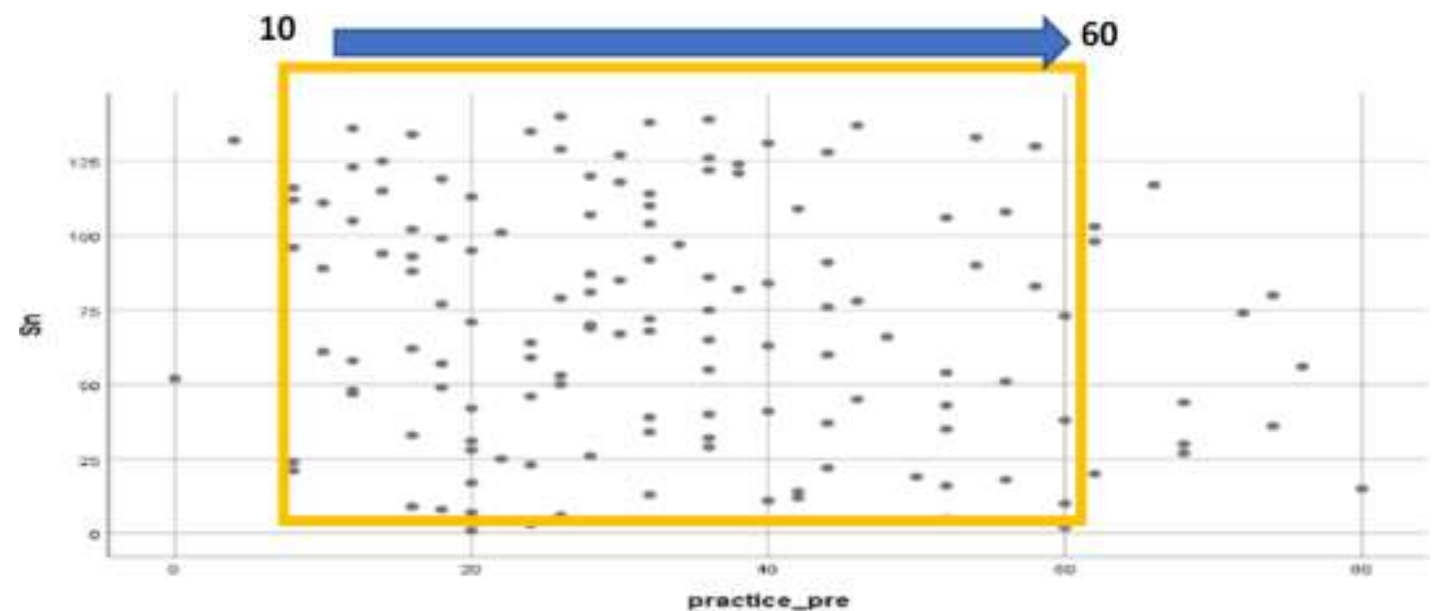

Figure (10): distribution of mean practices (Dry Lab) results before training

Fig (10) shows that the distribution of the practices score results before training is ranging between 10 to 60 for the trainees, and few of them, and few of them exceeded 60 to 80, the mean of distribution in table above (2.1) which equal 33.88, and the median was $32.0 \%$ and standard deviation was $17.82 \%$, that means there are some of trainees had previous practices while most of them have no experience. This may affect on the practical training; this requires consideration of all levels in training.

\section{Post-test Scoring among Trainees:}

There are $61.2 \%$ of study participants were had a very good practice, $36.7 \%$ had good practices, $1.43 \%$ had moderate practices, the mean average of practices was $82.32 \%$.

\section{Post-test Scoring among trainees in Dry Lab:}

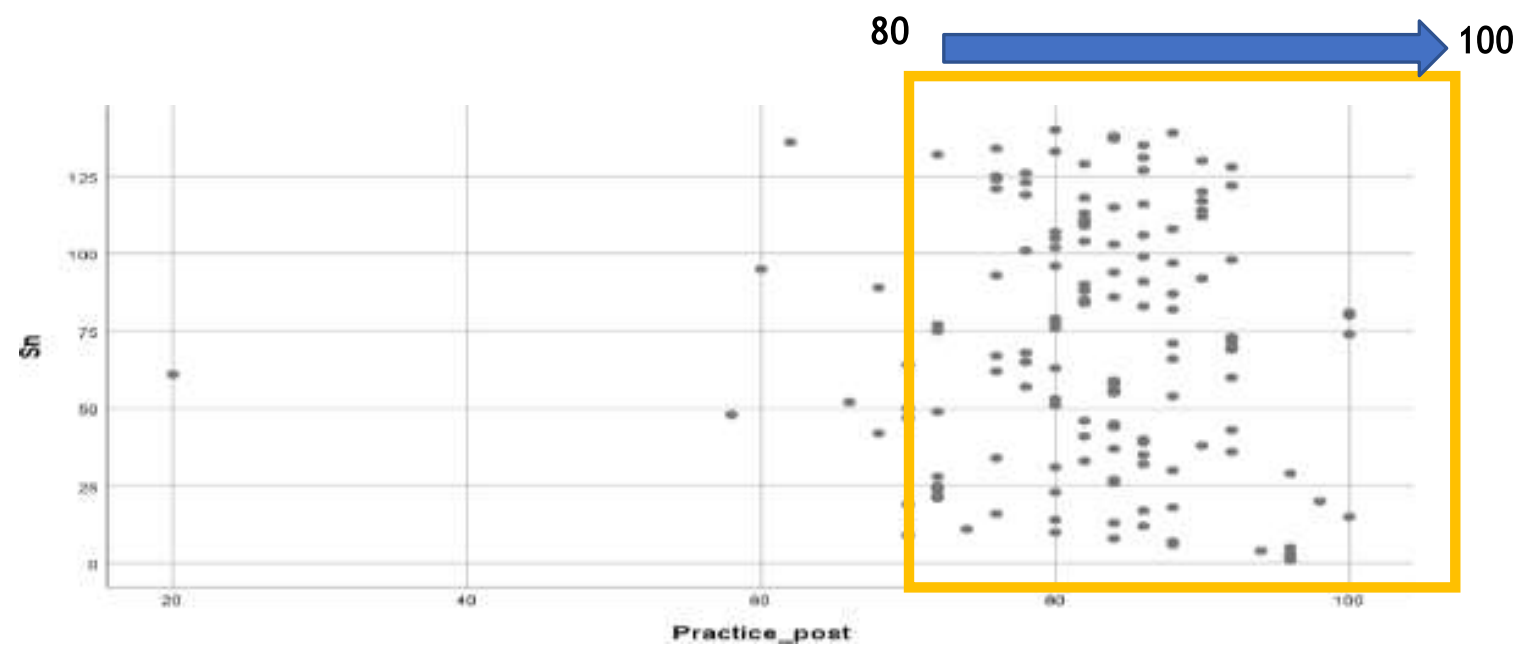

Figure (11): A. Post-test Scoring among trainees in Dry Lab 
Fig (11) shows that the distribution of the Practices score results after training is ranging between 80 to 100 for the trainees, the most participant result were between 75 to 95, and few of them exceeded 95, it's clear from the mean of distribution in table above (4) which equal 82.32 , and the median was $84.0 \%$ and standard deviation was $9.70 \%$, This results shows that there were a size of benefit of practices training. These results confirm the ability of trainers to deal with previous differences in perception and training effectiveness. This is consistent with the studies confirming the improvement in learning curve with previous MIS training (19.20).

\section{Change Percent between Pre and Post-testing among Trainees in Dry Lab:}

There are $33.1 \%$ of study participants improve their practices less than one hundred percent, $26.6 \%$ improve their practice from $101 \%$ to $200 \%$, and $24.5 \%$ improve their practice more than $300 \%$, while the mean average of change percent was $227.81 \%$.

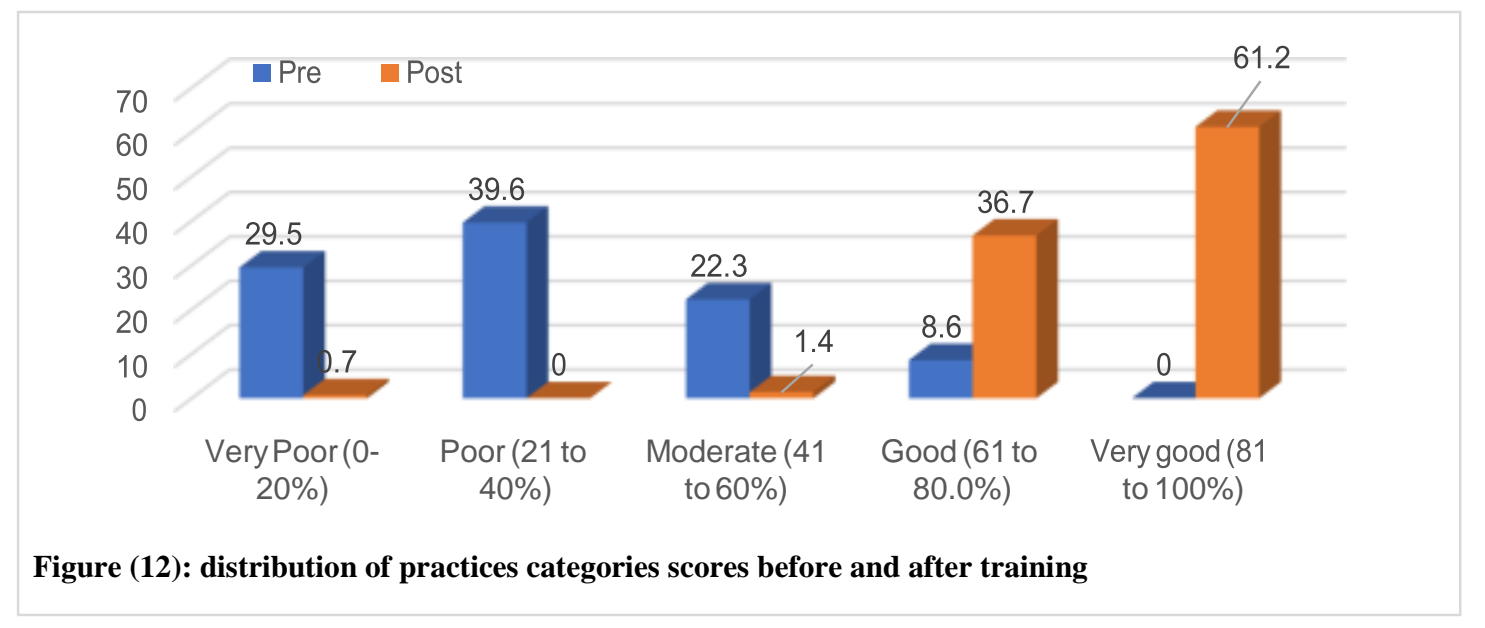

\section{Inferential Statistics between practices before and after training}

This improvement of practices training is statistically significant according to table 8 which mean there are statistical differences (sig. $\leq 0.05$ ). between Practices pre and post-test, the mean of practices in pre-test training was $33.88 \%$ while post- training was $82.32 \%$.

\begin{tabular}{|c|c|c|c|c|c|}
\hline Practices & N & Mean & Std & T & P-Value \\
\hline Before & 139 & 33.88 & 17.82 & \multirow{2}{*}{-36.251} & 0.001 \\
\hline After & 139 & 82.32 & 9.695 & & \\
\hline
\end{tabular}

Table (8) Differences between Practices before and after training 


\section{Distribution of Wet Lab scores of Trainees}

\section{III.1 Mean of Wet Lab scores among the trainees}

The GOALS scoring system was elected by researchers to assess the trainees in wet Lab on a laparoscopic simulator (as if simulating the real clinical sitting). Theses scores prove the validity of having the cognitive knowledge and dry lab before the wet lab.

Table (9) shows that the mean of Wet Lab scores for trainee were $84.0 \%$ according to the Wet Lab categorization most of the trainee had a good and very good scores with percent $95.0 \%$, only $2.9 \%$ had average scores while $2.1 \%$ between fail and pass scores

\begin{tabular}{|l|c|c|}
\hline \multicolumn{1}{|c|}{ Wet Lab Categorization } & Nu & \% \\
\hline Fail (Less than 60\%) & 2 & 1.4 \\
\hline Pass (From 60 to 69\%) & 1 & 0.7 \\
\hline Average (From 70 to 79\%) & 4 & 2.9 \\
\hline Good (From 80 to 89\%) & 113 & 81.3 \\
\hline Very Good (90\% and more) & 19 & 13.7 \\
\hline Total & $\mathbf{1 3 9}$ & $\mathbf{1 0 0 . 0}$ \\
\hline \multicolumn{2}{|l}{} \\
\hline
\end{tabular}

Table (9) Distribution of Wet Lab scores of Trainees

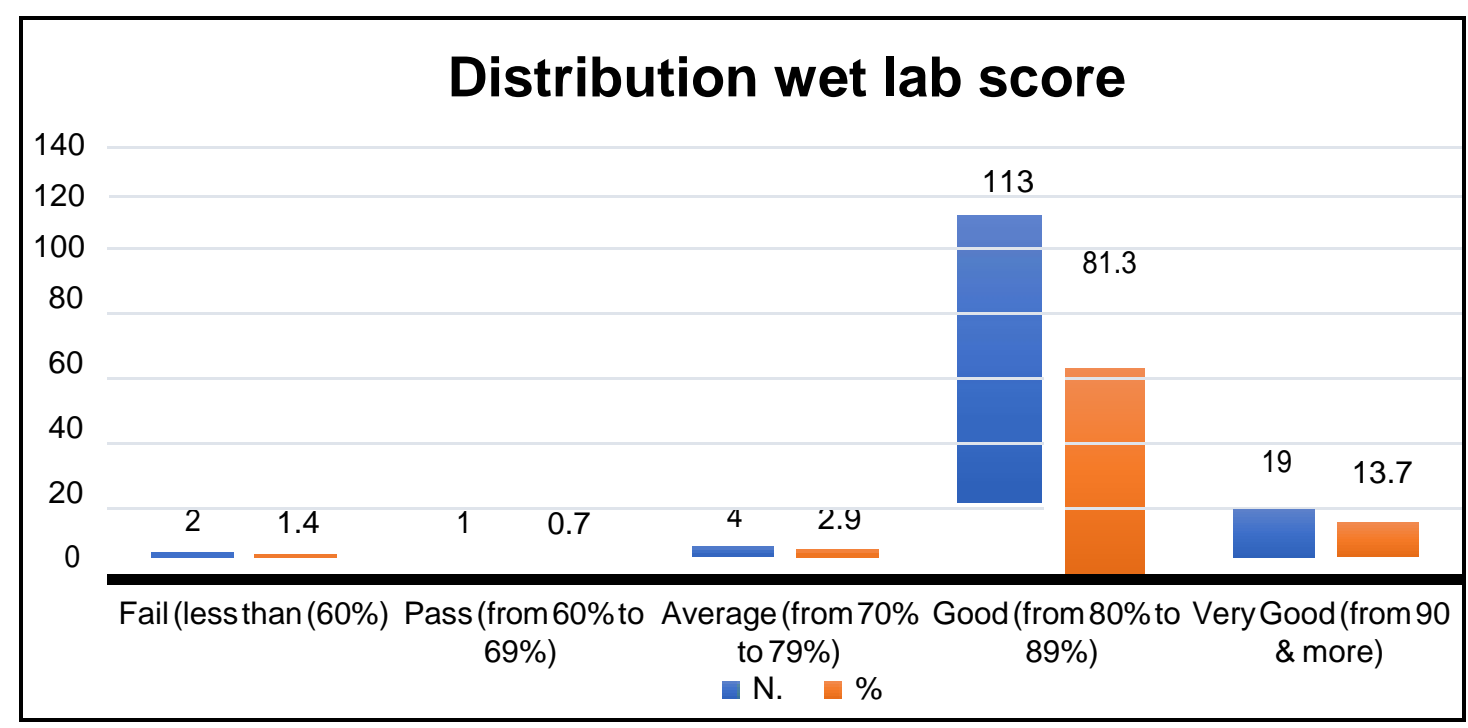

Figure (13): Wet lab scores among the trainees 


\section{IV: Correlation between Cognitive, Dry lab and Wet Lab}

Fig (13) showed that the mean score of cognitive was $72.14 \%$ m Dry lab $82.32 \%$ and Wet lab $84.1 \%$, and there is statistical relationship between both cognitive, Dry lab and Wet lab $R=0.383$ and the Sig. $\leq 0.05$.

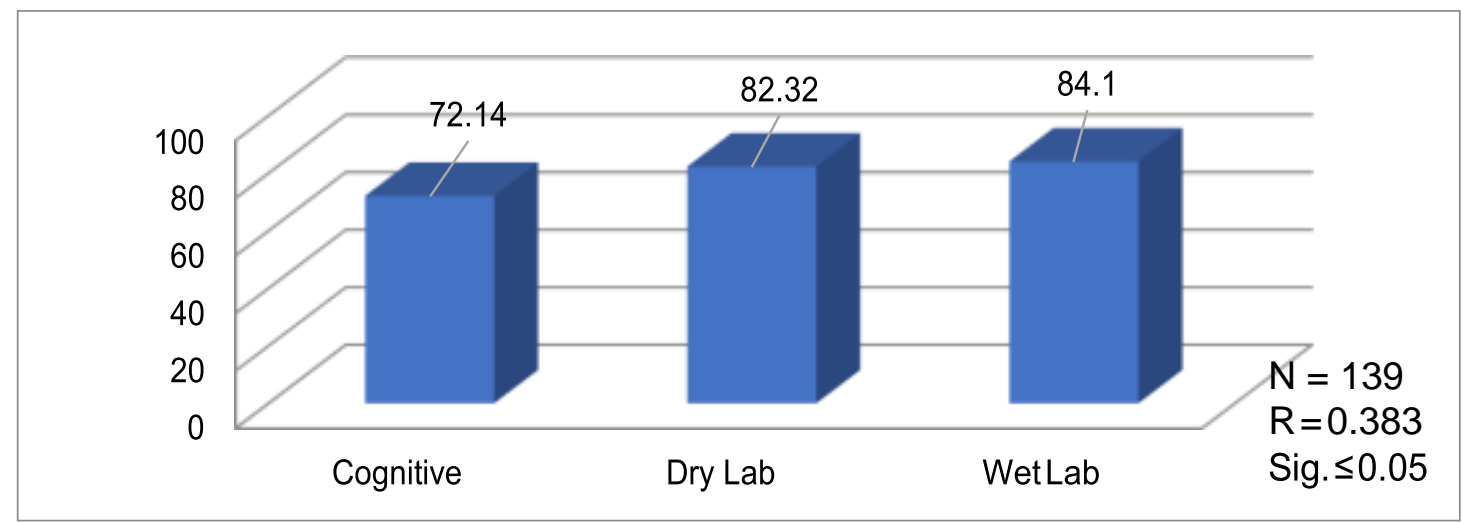

Figure (14): Distribution of mean score of cognitive Dry Lab and Wet Lab

\section{V: Construct Validity (how much the total scores correlate with the three-age group ie value of simulation in minimally invasive surgery)}

The trainees has been divided into three groups according to age. The first group was from 25 to 35 (:n:90) the second was from 36 to 45(n:17) and the third was from above 46 to 65 (n;31)

According to the Figure below there is no statistical differences between age group and the final score of overall training the mean average of the trainees ages less than 35 years old was $81.2 \%$ followed by the trainees above 45 years old $79.7 \%$ with very simple difference in mean with trainees aged between 35 years old to 45 years old $79.6 \%$. This could be interpreted that the trainees had got significant uniform benefits of training methodology despite number of trainees in each group!

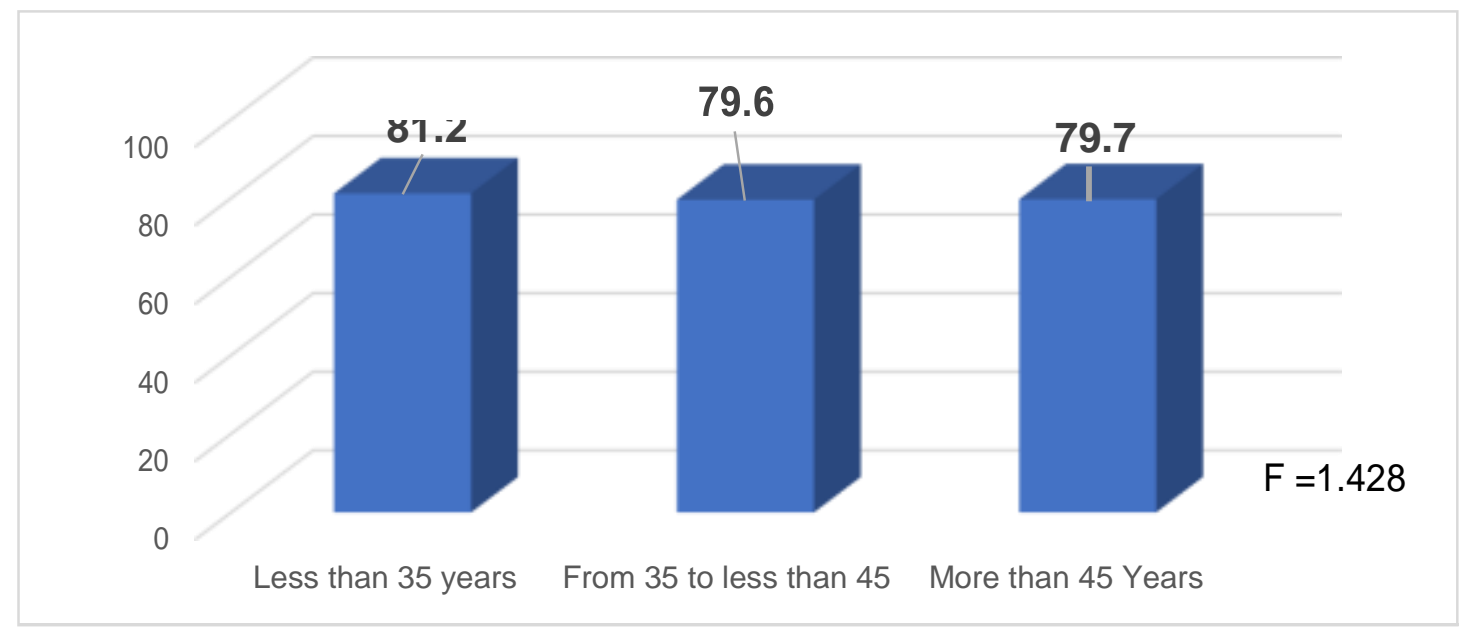

Figure (15)

This simply reflects how much this combined methodology of training (triangulation of cognitive knowledge, Dry lab and Wet Lab) can mostly fit trainees irrespective of the age of the surgeon. 


\section{Conclusion}

The triad of cognitive knowledge, physical simulator and a full Turkey biological model is a feasible, valid and effective methodology of training in MIS. Different age groups can achieve approximate scores inspite of different levels of experience. MISTEL evaluation scoring is stil a valid and objective tool in physical simulation assessment. However, the full Turkey model operating on a laparoscopic simulator is an invaluable adjunct to physical simulator and complementary to it where the trainee will do the same five tasks in addition to biological tissue handling, dissection, Veress needle and port insertion in addition to camera manipulation. Those are essentials to practice ergonomics. In spite of the fact that the Miller's pyramid is used to assess the clinical proficiency in clinical settings, still its main parameters can be used on full biological animal models.

\section{Acknowledgement:}

Authors do highly appreciate and honor the noble effort and support of the late Dr Mario Meinero the international and early founder of laparoscopy worldwide. As a memorial of Dr Mario we proudly mention that he built with us the MIS training curriculum and guidelines and started the training in the developed MIS training center. He coined for this research but unfortunately passed away during the early stages of this training!

Ms Suhaila Trazi the Director General of AAH was very enthusiastic in supporting all the logistics of training and the prerequisites of this study!

\section{References:}

1. Michele Tonutti et al. (2016) The role of technology in minimally invasive surgery: state of the art, recent developments and future directions. PMJ

2. Eliza M. Slama, Allen Silbergleit (2016), William Stewart Halsted: Father of the model for our current surgical training programs, Department of Surgery, St. Joseph Mercy Oakland, Pontiac, MI

3. HArsha V.et al 2013, 100 years of surgical education: The past, present, and future. Annals of surgery

4. Fried GM1 et al (2004), Proving the value of simulation in laparoscopic surgery, Ann Surg. 2004 Sep;240(3):518-25; discussion 525-8. PubMed

5. P. Vitish-Sharma et. Al, 2011, Acquisition of fundamental laparoscopic skills: is a box really as good as a virtual reality trainer? Int Journal of Surger, PubMed

6. Technical Skills Proficiency-Based Training Curriculum (2014). https://www.flsprogram.org >

7. Uploads 2014/02PDF

8. Gerald M et al 2004a, Validating Laparoscopic Simulation. Annals of Surgery Volume 240, Number 3, P.524

9. Gerald M. et al, 2004b, Proving the Value of Simulation in Laparoscopic Surgery, Annals of Surgery, Volume 240, Number 3 ,

10. Mulla M, Sharma D, Moghul M, Kailani O, Dockery J, Ayis S, Grange P (2012(;. Learning basic laparoscopic skills: a randomized controlled study comparing box trainer, virtual reality simulator, and mental training. J Surg Educ. 69:190-195. (PubMed)

11. Munz Y, Kumar BD, Moorthy K, Bann S, Darzi A. Laparoscopic virtual reality and box trainers: is one superior to the other? Surg Endosc. 2004; 18:485-494. (PubMed)

12. Archer SB1et al (2001), Bile duct injury during laparoscopic cholecystectomy: results of a national survey. Ann Surg. 2001 Oct;234(4):549-58; discussion 558-9.

13. Miller GE. (1990); The assessment of clinical skills/ competence/ performance. Acad Med 65:s63s67.

14. Vassiliou MV, et al,2006, The MISTELS program to measure technical skill in laparoscopic surgery: evidence for reliability. Surg endosc, PubMed

15. Williams et al., (2016) Miller's Pyramid and Core Competency Assessment: A Study in Relationship Construct Validity, JCEHP.

16. Edmundo Dediós Orozco, Carlos Dediós (2017), Training in Laparoscopic Surgery in Latin America, Journal of Gastrointestinal \& Digestive System 
17. Daniel J Scott 1, E Matt Ritter, Seifu T Tesfay, Elisabeth A Pimentel, Alykhan Nagji, Gerald M Fried (2008), Certification pass rate of $100 \%$ for fundamentals of laparoscopic surgery skills after proficiency-based training. PubMed.gov

18. Kramp KH et al 2015, Validity and reliability of global operative assessment of laparoscopic skills (GOALS) in novice trainees performing a laparoscopic cholecystectomy. J Surg Educ. 2015 MarApr;72(2):351-8. doi: 10.1016/j.jsurg.2014.08.006. Epub 2014 Oct 16.

19. Awais Amjad Malik et al,2016, Validation and reliability of Global Operative Assessment of Laparoscopic Skills for surgical residents and consultants JPMA, (National Hospital \& Medical Centre, Lahore. )

20. Fabio C M Torricelli, et al (2016), Impact of laparoscopic surgery training laboratory on surgeon's performance. Medicine World Journal of Gastrointestinal Surgery

21. Nagendran M, Toon CD, Davidson BR, Gurusamy KS. Laparoscopic surgical box model training for surgical trainees with no prior laparoscopic experience. Cochrane Database Syst Rev. 2014;(1):CD010479. [PubMed] 